\title{
Merging Policy Initiatives and Developmental Perspectives in Early Intervention
}

\section{Uniendo Iniciativas Políticas y Perspectivas de Desarrollo en la Atención Temprana}

\author{
Michael J. Guralnick \\ Center on Human Development and Disability. University of Washington, USA
}

Available online 31 August 2015

\begin{abstract}
The provision of early intervention services for vulnerable children and their families is now both accepted and expected by the international community. This article considers the importance of a developmental perspective as an essential guide to early intervention service systems. Emphasized in this framework are three critical features: relationship formation, the continuity of interventions, and the comprehensiveness of interventions. Guidance to early intervention systems design with respect to structural and values principles is also discussed. Future advances in early intervention may well depend upon the merging of these perspectives to create policy initiatives to enhance early intervention systems.
\end{abstract}

Key Words: Early Intervention; Policy; Developmental Perspectives.

Proporcionar servicios de Atención Temprana para niños vulnerables y para sus familias es algo actualmente no sólo aceptado sino también esperado por la comunidad internacional. Este artículo considera la importancia de adoptar una perspectiva evolutiva como guía esencial par el sistema de servicios de atención temprana. En este marco destacan tres características cruciales: el establecimiento de relaciones, la continuidad de las intervenciones y la comprensión de las mismas. Asimismo trata sobre la orientación del diseño de los sistemas de atención temprana en cuanto a estructura y principios de valores. Los futuros avances en atención temprana bien pueden depender de la fusión de estas perspectivas para la creación de iniciativas políticas de mejora de estos sistemas.

Palabras Clave: Atención Temprana; Política; Perspectivas de desarrollo.

Correspondence concerning this article should be addressed to: Michael J. Guralnick. Center on Human Development and Disability. University of Washington, Box 357920. Seattle, WA 98195-7920. Phone: (206) 543-2832. Fax: (206) 543-3417. E-mail: mjgural@u.washington.edu. CHDD Website: www.chdd.washington.edu. University Faculty Website: www.chdd.washington.edu/guralnick.html 
Early intervention initiatives have been based on the abundance of neurobiological and developmental evidence suggesting that early childhood provides a unique window of opportunity to alter children's developmental trajectories, with the potential to generate long-term benefits in many aspects of an individual's quality of life (Guralnick, 2011; Shonkoff \& Phillips, 2000). When joined by the results of numerous intervention studies demonstrating the benefits of early intervention for children at risk due to environmental (Guralnick, 2013) or biological (Guralnick, 2012) factors as well as those involving children with established developmental delays (Guralnick, in press, under review), early intervention practice is now both accepted and expected in high resource countries throughout the world. The international community has also recognized the value of early intervention for vulnerable children and their families establishing both a framework and set of initiatives for low-and-middle resource countries (World Health Organization \& UNICEF, 2012). Yet, despite this remarkable progress, the field of early intervention has now reached an important stage in its own development with respect to its ability to respond to pragmatic and humanitarian concerns and to support and strengthen families with vulnerable children. In this article, a conceptual framework and strategies to further enhance the effectiveness of community-based early intervention services are discussed.

\section{Background and Challenges}

Developmental science has provided the central framework guiding the design, implementation, and evaluation of specific intervention strategies and practices carried out within early intervention systems that has enabled interventionists to enhance the social and cognitive competence of young vulnerable children. Indeed, developmental pathways that influence the emerging competencies of typically developing children have now been well established and, of importance, both association and intervention studies have confirmed the relevance of these experientially-based pathways for vulnerable children in general (Guralnick, 2011). As discussed below, the application of developmental science to early intervention (including preventive interventions) has emphasized the importance of three critical features: relationship formation, continuity of intervention across the entire early childhood period, and comprehensiveness of intervention. All three features can only be carried out effectively within a family-centered context, as strengthening and supporting families is essential in order to maximize both short- and longer-term child outcomes.

Also guiding the development of early intervention systems has been general agreement with respect to a set of principles representing a combination of structural features (e.g., accountability procedures; surveillance systems) and values (e.g., inclusion; cultural competence) (Bruder, 2010; Guralnick, 2008; Vargas-Barón, 2013). These structural/values prin- ciples provide insight into the philosophical and ideological roots of early intervention and also incorporate the knowledge base of developmental and intervention science. Together they are capable of transforming day-to-day practices in a manner that effectively supports vulnerable children and their families.

Yet it is also the case that this transformation presents an extraordinary set of challenges to the early intervention community. More specifically, as exciting and important as these advances have been there has been insufficient attention given to the merging of structural/values principles with the perspective provided by developmental science and related intervention research. As suggested in this article, the absence of this merging or integration prevents the field of early intervention from realizing its full potential. The fact that structural/ values principles often operate in parallel with the perspective provided by developmental science creates systems with many inconsistencies. This article is intended to promote a greater awareness of this issue and to encourage those involved in early intervention systems design to establish a dialog intended to address this problem. To facilitate this dialog, I will first discuss critical features of developmental science as applied to early intervention followed by consideration of key structural/values principles. In the final section, I will indicate how merging these two perspectives and establishing corresponding policy initiatives will ultimately enhance early intervention systems.

\section{Developmental Science}

From a conceptual perspective, developmental science has relied heavily on systems models (e.g., Bronfenbrenner, 2001; Sameroff, 2009) that have identified pathways through which environmental or experiential influences at many levels influence children's development. The developmental psychopathology approach has extended this broader systems framework to atypical populations (Cicchetti \& Cohen, 2006; Lewis, 2000). More recently, the Developmental Systems Approach (DSA), relying extensively on these systems models and related empirical work, has directly applied systems concepts, networks, and principles to the field of early intervention (Guralnick, 2005, 2011). Figure 1 illustrates the main features of the DSA and highlights the three critical levels that mutually and reciprocally influence one another (level of the child; level of family patterns of interaction; level of family resources). Presented in the figure are the well-established pathways of experiential influences on children's development as well as the interactions that can occur among the various levels and components within levels. Despite the complexity of these pathways and the diverse interactions captured in Figure 1, the DSA nevertheless has clear and straightforward implications for early intervention. 
Figure 1

The Developmental Systems Approach illustrating levels, components, and interrelationships. Adapted from "Why Early Intervention Works: A Systems Perspective," by M. J. Guralnick, 2011, Infants \& Young Children, 24, pp. 6-28. Copyright 2011 Lippincott Williams \& Wilkins.

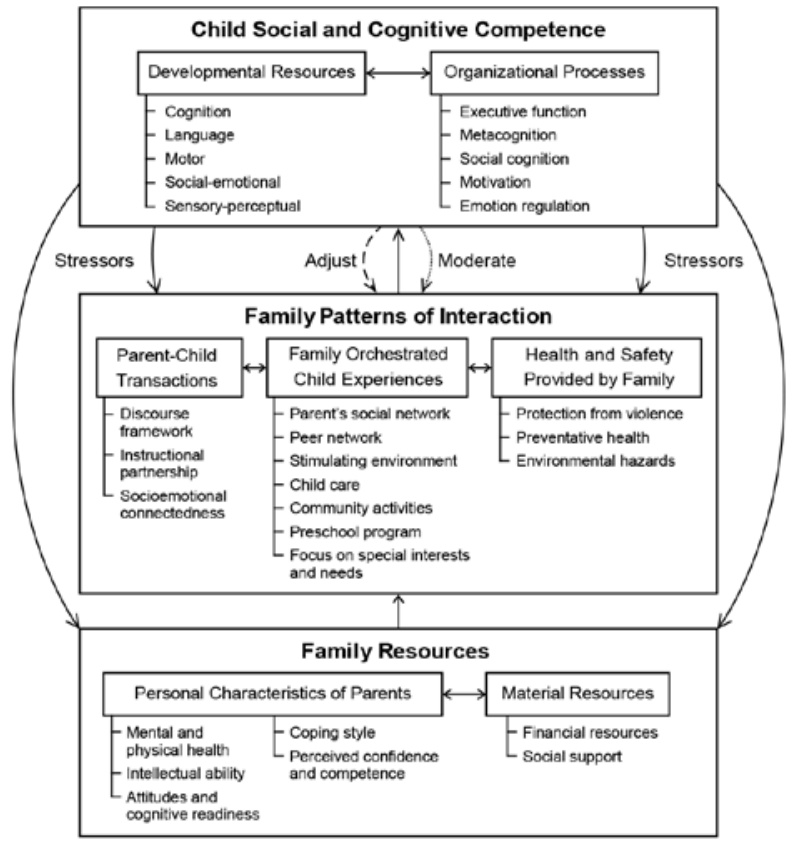

\section{Influence of Family Patterns of Interaction}

Specifically, the DSA suggests that early intervention is optimal if sufficient support is provided to families such that the quality of all three family patterns of interaction is maximized (see Figure 1). Establishing high quality parent-child transactions is most critical especially during the first three years of a child's life (Aksan, Kochanska \& Ortmann, 2006; Feldman, 2007). These parent-child transactions are typically organized around overlapping but yet distinct relationships formed as part of a discourse framework (e.g., Chouinard, 2007), an instructional partnership (e.g., Dieterich, Assel, Swank, Smith \& Landry, 2006; Pratt, Kerig, Cowan \& Cowan, 1988; Vygotsky, 1978), and socioemotional connectedness (e.g., Leerkes, Blankson \& O'Brien, 2009). The second major domain of family patterns of interaction consists of those child experiences organized by parents that contribute to children's development. Extensive evidence indicates that these community learning opportunities can have a substantial impact on children's developmental trajectories (e.g., Dunst, Hamby, Trivette, Raab \& Bruder, 2000). Careful selection of child care and preschool programs is one component of this domain. High quality centerbased programs in particular have consistently produced benefits with respect to pre-academic skills for various groups of vulnerable children (e.g., McCartney, Dearing, Taylor \& Bub, 2007; Phillips \& Meloy, 2012). Of importance, these positive findings are no substitute for high quality parent-child transactions continuing across the early childhood period. In their absence, long-term effects of programs with a pre-academic focus are less likely to occur (Duncan \& Magnuson, 2013). Of course, families' attention to their children's health and safety is also required. Especially in chaotic environments, failure to do so can create what is generally referred to as "toxic stress" adversely affecting developmental processes that underlie children's development including emotion regulation and executive function (Thompson, 2014).

The key point here is that the components of family patterns of interaction consisting of parent-child transactions, family orchestrated child experiences, and health and safety provided by the family, constitute the focus of early intervention efforts within the DSA. Indeed, these are the developmental pathways of experiential influence that have been well established through both developmental and intervention science. Each component of family patterns of interaction constitutes a potential target of early intervention in support of a family's efforts to promote their child's development. Assessment instruments to determine the status for virtually all of these components of family patterns of interaction are available as are many corresponding intervention strategies (e.g., Spiker, Hebbeler \& Mallik, 2005). Other strategies are being developed on a regular basis.

Improving the quality of each component of family patterns of interaction has the potential to contribute to a process capable of creating a cumulative impact on children's social and cognitive competence. Accordingly, this emphasizes the critical nature of comprehensiveness in any early intervention system and the need for surveillance systems throughout the early childhood period to address intervention needs as they emerge (continuity). With respect to the latter, risk and protective factors change substantially over time due to both child and family circumstances. Early intervention systems must be responsive to and even anticipate issues that may emerge. Finally, the quality of relationships in general but especially the three parent-child transactions noted above are critical. Although these relationship constructs present complex assessment issues, researchers have established reliable and valid measures of sensitive-responsiveness, affective warmth, and engagement that, taken together, can map on to the contexts characteristic of each type of parent-child transaction (see Bornstein \& Manian, 2013).

\section{Influence at the Level of Child Development: Biological Risk and Developmental Delay}

For children at biological risk and those with established developmental delays families constantly face day-to-day challenges to provide optimal family patterns of interaction (Bernheimer \& Weisner, 2007; Crnic, Pedersen Y Arbona, Baker $\&$ Blacher, 2009). Indeed, as represented by the dashed line between the levels of child development and family patterns of interaction in Figure 1, adjustments and accommodations frequently occur, many of which are quite successful in maintaining high quality interactions (Watson, Hayes \& RadfordPaz, 2011). Yet biological constraints on children's develop- 
ment affecting their developmental resources (see Figure 1, e.g., cognition, language) as well as their organizational process (e.g., executive function, emotion regulation) create patterns of children's social and cognitive competencies (behaviors) that can easily reduce the quality of family patterns of interaction (e.g., mismatched language input; limited community participation). These child-specific stressors (see arrows in Figure 1 from level of child development to the level of family patterns of interaction) vary extensively with the nature and severity of specific child vulnerabilities.

Fortunately, particularly in recent years, developmental science has made major advances in understanding how biological constraints associated with children at biological risk such as preterm birth (Sansavini, Guarini \& Caselli, 2011) as well as those with etiologic-specific genetic disorders such as Down syndrome, Williams syndrome, or Fragile X syndrome are likely to influence children's developmental and behavioral patterns (Burack, Hodapp, Iarocci \& Zigler, 2012; KarmiloffSmith, 2011; Karmiloff-Smith, Casey, Massand, Tomalski \& Thomas, 2014). Development emerges over time in an environmental context as children adapt to their biological constraints using the tools available to them (developmental resources and organizational processes) to achieve their goals. Of importance, our knowledge of the often unique developmental patterns that result from these processes can be extremely useful in both understanding the difficulties parents are likely to experience in providing optimal family patterns of interaction and in developing intervention strategies when family patterns of interaction are perturbed in order to maximize their quality (Fidler, Most \& Philofsky, 2009).

Clearly, early intervention constitutes a problem-solving process engaging all involved, especially the immediate and extended family. Information about the specific characteristics of children's development, including etiologic-specific information when available, can inform that problem-solving process and help individuals gain a better understanding of the underlying influences on children's behavior and development. These child-characteristics may also help families and the intervention team to better understand why some interventions may not be successful. Unquestionably, genetic factors such as those that govern the extent to which children are susceptible to experiential influences (Belsky \& Pluess, 2013) as well as children's prior experiences can moderate the effects of early intervention. This moderating feature is indicated in the DSA by the dotted line between the levels of child development and family patterns of interaction in Figure 1. This is a particularly vexing problem for children with autism as similar early interventions often produce vastly different outcomes (Rogers \& Vismara, 2008). Further work on the underlying biology of this complex neurodevelopmental disorder may contribute to the identification of subgroups sharing certain features. In turn, this may generate creative strategies that will ultimately strengthen all the components of family patterns of interaction.

\section{Influence of Family Resources: Environmental Risk}

A family's resources (see Figure 1) constitute the underlying structure capable of supporting high quality family patterns of interaction. Although details of how these influences operate can be found elsewhere (Bradley \& Corwyn, 2004; Guralnick, 2013), many families display risk factors for clusters of the components noted in Figure 1. These components have been organized in terms of the personal characteristics of the parents and material resources. Chronic poverty is perhaps the most corrosive, capable of influencing all other components. Alternatively, high quality social supports can serve as a buffer for many of these risk factors, therefore constituting an important protective factor (Guralnick, Hammond, Neville \& Connor, 2008; Plant \& Sanders, 2007; Raspa, Bailey, Bann \& Bishop, 2014). These environmental risk factors typically influence children's social and cognitive competencies indirectly, operating through family patterns of interaction. The associations among environmental risk factors, poorer quality family patterns of interaction, and children's competence is well-established (Rodríguez \& Tamis-Lemonda, 2011). Intervention science has utilized this framework and been able to improve numerous outcomes for children at environmental risk (Camilli, Vargas, Ryan \& Barnett, 2010; Guralnick, 2013).

The co-occurrence of family resource risk factors, especially poverty, for children at biological risk as well as those with developmental delays is also well established (Emerson \& Hatton, 2009). Moreover, irrespective of initial levels of environmental risk, child-specific characteristics can exacerbate any problems at the level of family resources as seen with respect to adverse influences on parent stress and other aspects of the parents' physical and mental health (Gerstein, Crnic, Blacher \& Baker, 2009). The burden of additional financial costs can also add stress affecting all components of family resources (Olsson \& Hwang, 2008).

\section{Summary}

Taken together, the pressure to establish or maintain high quality family patterns of interaction for families of vulnerable children is considerable. For children at biological risk or with established delays, child-specific characteristics may well create stressors that influence not only family patterns of interaction but family resources as well. For children at risk due to environmental factors, family patterns of interaction are compromised primarily from the influence of components at the level of family resources. Again, we see the importance of taking a comprehensive approach to early intervention to address as many components as needed at all levels. Within systems frameworks in general, levels and components are all interconnected and the greatest impact will result from cumulative effects.

It is important at this point to acknowledge how difficult it is to alter many components of family resources in a reasonable period of time. Many family resource problems are long- 
standing and are constrained by cultural attitudes and limited resources available in communities to support families of vulnerable children. Intervention must also be extremely sensitive to family privacy. Trusting and respectful relationships with families must be established by the intervention team before any progress can be achieved, especially when addressing influences at the level of family resources.

\section{Structure and Values: Principles}

An international consensus appears to have been achieved in recent years with respect to principles guiding early intervention based on structural features, values that should influence the design of programs, and the relevance of a developmental framework to early intervention system design (see Guralnick, 2008). As discussed in the next section, special attention to these principles is critical in order to further enhance the quality and effectiveness of community-based early intervention programs. Of considerable importance is the principle related to integration and coordination (see Table 1). Historically, and generally the case today as well, various sectors including health, education, social services, child care, as well as many others have tended to operate in an independent and separate fashion. The components at all three levels of the DSA rely upon these many service and support entities, and effective early intervention requires their integration and coordination. This can be accomplished only through thoughtfully considered administrative processes and a shared vision. Vargas-Barón (2013) has identified important strategies to address this issue.

\section{Table 1}

Principles guiding early intervention systems design (based on Guralnick, 2008).

\begin{tabular}{|ll|}
\hline \multicolumn{1}{|c|}{ Principles: Structure and Values } \\
1. & Developmental Framework \\
2. & Integration and Coordination \\
3. & Inclusion \\
4. & Early Detection and Identification \\
5. & Surveillance and Monitoring \\
6. & Individualized \\
7. & Evaluation and Feedback \\
8. & Cultural Competence \\
9. & Evidence-Based Practices \\
10. & Systems Perspective \\
\hline
\end{tabular}

Following this more closely, a major component of any well-coordinated and integrated system is to ensure that early detection and identification procedures are in place along with strategies for surveillance and monitoring of those children who are at risk for delays. Implementation of these principles relative to early identification and surveillance relies upon highly sophisticated risk registries and screening systems. Cumulative risk indices are also available, especially for children at risk due to environmental factors (Vernon-Feagans, Cox \& Family Life Project Key Investigators, 2013). Of importance, the development of screening tools can be scaled-up for large populations in a feasible and cost-effective way for all children at risk (Bricker, Macy, Squires \& Marks, 2013). Moreover, our increasing capability to screen for a larger array of genetic disorders as well as the recent emphasis to screen children for autism spectrum disorder at early ages in many contexts (e.g., home, health care, child care) will further increase our capacity to provide early intervention services as soon as possible.

Two principles are closely linked to values. With roots in equity and human rights issues (Brown \& Guralnick, 2012; Vargas-Barón, 2013) the principle of inclusion has emerged as a central value not only relevant to the early childhood period but for all stages throughout the life span. Creating a sense of belonging to the larger community and organizing early intervention services and supports accordingly is often a challenging task in many communities, but if carried out effectively can help support children's social development (Guralnick, Connor, Neville \& Hammond, 2006). Similarly, the principle focused on ensuring that interventionists are highly sensitive to a family's goals and values is critical. In its absence very little will be accomplished. Given the diversity of families in almost all communities, high levels of sensitivity to a family's cultural values in particular will be required.

Other agreed upon principles relate to the approaches taken to maximize the quality and effectiveness of the day-to-day practices of early intervention. Long established is the principle related to individualizing interventions. The components of the DSA can be employed to guide the gathering of assessment information with respect to the risk and protective status for each component that forms the basis for individualizing interventions. The related principle of selecting intervention strategies based on these assessments that are evidence-based is equally well established. By linking evidence-based intervention strategies to the assessment information provided by each of the DSA components, a more conceptually and empirically coherent and valid approach to intervention can be achieved. When combined with the principle requiring a strong evaluation and feedback process, a high level of efficient and effective problem solving by the early intervention team will likely emerge.

The overarching principle of maintaining a systems perspective binds all of these principles into a well-integrated framework. Effective implementation of this principle requires a level of leadership which actively engages in advocacy and identifies areas in need of further development in order to maximize all components of family patterns of interaction. Issues of governance of an early intervention system, setting standards and developing regulations, actively recruiting resources, and carrying out strategic planning are all central activities that require a systems perspective. When conducted in the context of a developmental framework, policy initiatives will emerge that are capable of maximizing the quality of early intervention systems. 


\section{Merging Policy Initiatives and Developmental Perspectives}

Implementation of these principles can be found in many early intervention systems in numerous countries (Bruder \& Guralnick, 2012). Yet it is fair to state that effective implementation is far from complete. Indeed, despite the extensive intervention science indicating the benefits of early intervention, the need for new initiatives to more effectively realize these principles and maximize their application in early intervention practice is evident even in high resource countries (Bruder, 2010; Hebbeler, Spiker \& Kahn, 2012). It is important to emphasize that when new initiatives are being considered, guidance provided by a developmental perspective is essential. Despite some differences of opinion regarding the application of behavioral and other structured approaches to early intervention, the developmental perspective is considered to be a central principle within a broader systems framework (Guralnick, 2008).

Accordingly, it is the developmental perspective that can be merged with other principles when policy initiatives are established to enhance early intervention services and supports. Specifically, as suggested in the DSA, in order to maximize children's social and cognitive competence the components of family patterns of interaction must be as optimal as possible. Although much can be accomplished at that level, the risk and protective factors for components of a family's resources must also be considered. Consequently, policy initiatives should be generated when difficulties are evident in maximizing the quality of any of these components. For example, policy initiatives addressing professional training should be designed to ensure that evidence-based strategies are directly linked to each of the DSA components. Similarly, optimizing parentchild transactions requires attention to developing relationships and this constitutes another professional training as well as curriculum development activity. Other policy initiatives may be generated if learning activities involving a diverse array of peers are restricted by the educational setting. Supporting peer networks is a vital family-orchestrated level experience and policies may need to be developed to enhance the child's participation in inclusive activities. Furthermore, a common problem is difficulty with respect to multi-sectoral integration and coordination. As noted, integration and coordination is essential in order to provide comprehensive services (i.e., addressing as many DSA components as needed) to achieve a maximum cumulative effect. Consequently, when problem-solving activities to maximize family patterns of interaction encounter barriers, it may well require the generation of policy initiatives that are further guided by well-accepted intervention principles. As suggested in this article, it is this interplay of policy initiatives and principles, particularly emphasizing a developmental perspective that will allow our field to move forward and improve the well-being of vulnerable young children and their families.

\section{References}

1. Aksan, N., Kochanska, G. \& Ortmann, M. R. (2006). Mutually responsive orientation between parents and their young children: Toward methodological advances in the science of relationships. Developmental Psychology, 42, 833-848. http://dx.doi.org/10.1037/0012-1649.42.5.833

2. Belsky, J. \& Pluess, M. (2013). Genetic moderaton of early child-care effects on social functioning across childhood: A developmental analysis. Child Development, 84, 1209-1225. http://dx.doi.org/10.1111/cdev.12058

3. Bernheimer, L. P. \& Weisner, T. S. (2007). "Let me just tell you what I do all day...". Infants \& Young Children, 20, 192-201. http://dx.doi.org/10.1097/01. IYC.0000277751.62819.9b

4. Bornstein, M. H. \& Manian, N. (2013). Maternal responsiveness and sensitivity reconsidered: Some is more. Development and Psychopathology, 25, 957-971. http://dx.doi.org/10.1017/S0954579413000308

5. Bradley, R. H. \& Corwyn, R. F. (2004). "Family process" investments that matter for child well-being. In A. Kalil \& T. Deleire (Eds.), Family investment in children's potential (pp. 1-32). Mahwah, NJ: Lawrence Erlbaum.

6. Bricker, D., Macy, M., Squires, J. \& Marks, K. (2013). Developmental screening in your community. Baltimore, MD: Paul H. Brookes.

7. Bronfenbrenner, U. (2001). Bioecological theory of human development. In N. J. Smelser \& B. P. Baltes (Eds.), International encyclopedia of the social and behavioral sciences (Vol. 10, pp. 6963-6970). New York, NY: Elsevier. http:// dx.doi.org/10.1016/B0-08-043076-7/00359-4

8. Brown, S. E. \& Guralnick, M. J. (2012). International human rights to early intervention for infants and young children with disabilities. Infants \& Young Children, 25, 270-285. http://dx.doi.org/10.1097/IYC.0b013e318268fa49

9. Bruder, M. B. (2010). Early childhood intervention: A promise to children and families for their future. Exceptional Children, 76, 339-355. http://dx.doi. org/10.1177/001440291007600306

10. Bruder, M. B. \& Guralnick, M. J. (2012). From the editor. Infants \& Young Children, 25, 267-269. http://dx.doi. org/10.1097/IYC.0b013e31826d8242

11. Burack, J. A., Hodapp, R., Iarocci, G. \& Zigler, E. (Eds.), (2012). The Oxford handbook of intellectual disabilities and development. New York, NY: Oxford University Press.

12. Camilli, G., Vargas, S., Ryan, S. \& Barnett, W. S. (2010). Meta-analysis of the effects of early education interventions on cognitive and social development. Teachers College Record, 112, 579-620. Retrieved from: http://www. tcrecord.org/library/abstract.asp?contentid=15440.

13. Chouinard, M. M. (2007). Children's questions: A mechanism for cognitive development. Monographs of the Society for Research in Child Development, 72, 1-112. http://dx.doi.org/10.1111/j.1540-5834.2007.00412.x 
14. Cicchetti, D. \& Cohen, D. (2006). Development and psychopathology. In D. Cicchetti, \& D. Cohen (Eds.), Developmental psychopathology: Vol. 1. Theory and methods (2nd ed., pp. 1-23). Hoboken, NJ: John Wiley \& Sons.

15. Crnic, K. A., Pedersen Y Arbona, A., Baker, B. \& Blacher, J. (2009). Mothers and fathers together: Contrasts in parenting across preschool to early school age in children with developmental delays. In L. M. Glidden \& M. M. Seltzer (Eds.), International Review of Research in Mental Retardation (Vol. 37, pp. 1 - 30). St. Mary's City, MD: Elsevier.

16. Dieterich, S. E., Assel, M. A., Swank, P., Smith, K. E. \& Landry, S. H. (2006). The impact of early maternal verbal scaffolding and child language abilities on later decoding and reading comprehension skills. Journal of School Psychology, 43, 481-494. http://dx.doi.org/10.1016/j. jsp.2005.10.003

17. Duncan, G. J. \& Magnuson, K. (2013). Investing in preschool programs. Journal of Economic Perspectives, 27, 109-132. http://dx.doi.org/10.1016/j.jsp.2005.10.003

18. Dunst, C. J., Hamby, D., Trivette, C. M., Raab, M. \& Bruder, M. B. (2000). Everyday family and community life and children's naturally occurring learning opportunities. Journal of Early Intervention, 23, 151-164. http://dx.doi. org/10.1177/10538151000230030501

19. Emerson, E. \& Hatton, C. (2009). Socioeconomic position, poverty, and family research. In L. M. Glidden \& M. M. Seltzer (Eds.), International Review of Research in Mental Retardation (Vol. 37, pp. 95 - 130). St. Mary's City, MD: Elsevier.

20. Feldman, R. (2007). Parent-infant synchrony and the construction of shared timing; physiological precursors, developmental outcomes, and risk conditions. Journal of Child Psychology and Psychiatry, 48, 329-354. http:// dx.doi.org/10.1111/j.1469-7610.2006.01701.x

21. Fidler, D. J., Most, D. \& Philofsky, A. D. (2009). The Down syndrome behavioural phenotype: Taking a developmental approach. Down Syndrome Research and Practice, 12, 37-44.

22. Gerstein, E. D., Crnic, K. A., Blacher, J. \& Baker, B. L. (2009). Resilience and the course of daily parenting stress in families of young children with intellectual disabilities. Journal of Intellectual Disability Research, 53, 981-997. http://dx.doi.org/10.1111/j.1365-2788.2009.01220.x

23. Guralnick, M. J. (Ed.). (2005). The developmental systems approach to early intervention. Baltimore, MD: Brookes.

24. Guralnick, M. J. (2008). International perspectives on early intervention: A search for common ground. Journal of Early Intervention, 30, 90-101. http://dx.doi.org/10.1177/1053815107313483

25. Guralnick, M. J. (2011). Why early intervention works: A systems perspective. Infants \& Young Children, 24, 6-28. http://dx.doi.org/10.1097/IYC.0b013e3182002cfe
26. Guralnick, M. J. (2012). Preventive interventions for preterm children: Effectiveness and developmental mechanisms. Journal of Developmental and Behavioral Pediatrics, 33, 352-364. http://dx.doi.org/10.1097/ DBP.0b013e31824eaa3c

27. Guralnick, M. J. (2013). Developmental science and preventive interventions for children at environmental risk. Infants \& Young Children, 26, 270-285. http://dx.doi.org/10.1097/IYC.0b013e3182a6832f

28. Guralnick, M. J. (in press). Early intervention for young children with developmental delays: Contributions of the developmental systems approach. In H. Sukkar, J. Kirby, \& C. Dunst (Eds.), Working with Families of Young Children. Routledge Publishing.

29. Guralnick, M. J. (under review). Early intervention for children with intellectual disabilities: An update. Manuscript submitted for publication.

30. Guralnick, M. J., Connor, R. T., Neville, B. \& Hammond, M. A. (2006). Promoting the peer-related social development of young children with mild developmental delays: Effectiveness of a comprehensive intervention. American Journal on Mental Retardation, 111, 336-356.

31. Guralnick, M. J., Hammond, M. A., Neville, B. \& Connor, R. T. (2008). The relationship between sources and functions of social support and dimensions of child- and parent-related stress. Journal of Intellectual Disability Research, 52, 1138-1154. http://dx.doi.org/10.1111/j.13652788.2008.01073.X

32. Hebbeler, K., Spiker, D. \& Kahn, L. (2012). Individuals with Disabilities Education Act's early childhood programs: Powerful vision and pesky details. Topics in Early Childhood Special Education, 31, 199-207. http:// dx.doi.org/10.1177/0271121411429077

33. Karmiloff-Smith, A. (2011). Static snapshots versus dynamic approaches to genes, brain, cognition, and behavior in neurodevelopmental disabilities. International Review of Research in Developmental Disabilities, 40, 1-15. http:// dx.doi.org/10.1016/B978-0-12-374478-4.00001-0

34. Karmiloff-Smith, A., Casey, B. J., Massand, E., Tomalski, P. \& Thomas, M. S. C. (2014). Environmental and genetic influences on neurocognitive development: The importance of multiple methodologies and time-dependent intervention. Clinical Psychological Science, 2, 628-632. http:// dx.doi.org/10.1177/2167702614521188

35. Leerkes, E. M., Blankson, N. \& O’Brien, M. (2009). Differential effects of maternal sensitivity to infant distress and nondistress on social-emotional functioning. Child Development, 80, 762-775. http://dx.doi.org/10.1111/j.14678624.2009.01296.x

36. Lewis, M. (2000). Toward a development of psychopathology: Models, definitions, and prediction. In A. J. Sameroff, M. Lewis, \& S. Miller (Eds.), Hand- 
book of developmental psychopathology (pp. 3-22). New York, NY: Kluwer Academic/Plenum Publishers. http://dx.doi.org/10.1007/978-1-4615-4163-9 1

37. McCartney, K., Dearing, E., Taylor, B. A. \& Bub, K. L. (2007). Quality child care supports the achievement of low-income children: Direct and indirect pathways through caregiving and the home environment. Journal of Applied Developmental Psychology, 28, 411-426. http://dx.doi.org/10.1016/j.appdev.2007.06.010

38. Olsson, M. B. \& Hwang, C. P. (2008). Socioeconomic and psychological variables as risk and protective factors for parental well-being in families of children with intellectual disabilities. Journal of Intellectual Disability Research, 52, 1102-1113. http://dx.doi.org/10.1111/j.13652788.2008.01081.x

39. Phillips, D. A. \& Meloy, M. E. (2012). High-quality schoolbased pre-K can boost early learning for children with special needs. Exceptional Children, 78, 471-490.

40. Plant, K. M. \& Sanders, M. (2007). Predictors of care-giver stress in families of preschool-aged children with developmental disabilities. Journal of Intellectual Disability Research, 51, 109-124. http://dx.doi.org/10.1111/j.13652788.2006.00829.x

41. Pratt, M. W., Kerig, P., Cowan, P. A. \& Cowan, C. P. (1988). Mothers and fathers teaching 3-year-olds: Authoritative parenting and adult scaffolding of young children's learning. Developmental Psychology, 24, 832-839. http:// dx.doi.org/10.1037/0012-1649.24.6.832

42. Raspa, M., Bailey, D. B., Bann, C. \& Bishop, E. (2014). Modeling family adaptation to Fragile X syndrome. American Journal on Intellectual and Developmental Disabilities, 119, 33-48. http://dx.doi.org/10.1352/1944-7558$\underline{119.1 .33}$

43. Rodriguez, E. T. \& Tamis-Lemonda, C. S. (2011). Trajectories of the home learning environment across the first 5 years: Associations with children's vocabulary and literacy skills at prekindergarten. Child Development, 82, 10581075. http://dx.doi.org/10.1111/j.1467-8624.2011.01614.x

44. Rogers, S. J. \& Vismara, L. A. (2008). Evidence-based comprehensive treatments for early autism. Journal of Clinical Child \& Adolescent Psychology, 37, 8-38. http://dx.doi.org/10.1080/15374410701817808

45. Sameroff, A. J. (2009). The transactional model. In A. J. Sameroff(Ed.), The transactional model of development (pp. 3-21). Washington,DC:AmericanPsychologicalAssociation http://dx.doi.org/10.1037/11877-001
46. Sansavini, A., Guarini, A. \& Casellli, M. C. (2011). Preterm birth: Neuropsychological profiles and atypical developmental pathways. Developmental Disabilities Research Reviews, 17, 102-113. http://dx.doi.org/10.1002/ddrr.1105

47. Shonkoff, J. P. \& Phillips, D. A. (2000). From neurons to neighborhoods: The science of early child development. Committee on Integrating the Science of Early Childhood Development. Washington, DC: National Academy Press.

48. Spiker, D., Hebbeler, K. \& Mallik, S. (2005). Developing and implementing early intervention programs for children with established disabilities. In M. J. Guralnick (Ed.), The developmental systems approach to early intervention (pp. 305-349). Baltimore, MD: Brookes.

49. Thompson, R. A. (2014). Stress and child development. The Future of Children, 24, 41-59. http://dx.doi.org/10.1353/ foc. 2014.0004

50. Vargas-Barón, E. (2013). Building and strengthing national systems for early childhood development. In P. R. Britto, P. L. Engle \& C. M. Super (Eds.), Handbook of Early Childhood Development Research and Its Impact on Global Policy (pp. 443-466). New York, NY: Oxford University Press. http://dx.doi.org/10.1093/acprof :oso/9780199922994.003.0024

51. Vernon-Feagans, L., Cox, M. \& Family Life Project Key Investigators. (2013). The family life project: An epidemiological and developmental study of young children living in poor rural communities. Monographs of the Society for Research in Child Development, 78, 1-108. http://dx.doi. org/10.1111/mono.12047

52. Vygotsky, L. S. (1978). Mind in society. Cambridge, MA: Harvard University Press.

53. Watson, S. L., Hayes, S. A. \& Radford-Paz, E. (2011). "Diagnose Me Please!" A review of research about the journey and initial impact of parents seeking a diagnosis of developmental disability for their child. In R. M. Hodapp (Ed.), International Review of Research in Developmental Disabilities (Vol. 41, pp. 31-71). San Diego, CA: Academic Press/Elsevier. http://dx.doi.org/10.1016/B978-0-12-386495-6.00002-3

54. World Health Organization \& UNICEF. (2012). Early childhood development and disability: A discussion paper. Malta: World Health Organization.

Received 7 January 2015 Received in revised form 27 March 2015 Accepted 10 April 2015 